\title{
A Somatically Mutated Human Antiganglioside IgM Antibody that Induces Experimental Neuropathy in Mice Is Encoded by the Variable Region Heavy Chain Gene, V1-18
}

\author{
Hugh J. Willison, ${ }^{*}$ Graham M. O’Hanlon, ${ }^{*}$ Gary Paterson, ${ }^{*}$ Jean Veitch, ${ }^{\star}$ George Wilson, ${ }^{\star}$ Mark Roberts, ${ }^{\ddagger}$ Teresa Tang, ${ }^{\ddagger}$ \\ and Angela Vincent ${ }^{\ddagger}$ \\ *Department of Neurology, University of Glasgow, Institute of Neurological Sciences, Southern General Hospital, Glasgow, G51 4TF; \\ and ${ }^{\ddagger}$ Department of Clinical Neurology, University of Oxford, Institute of Molecular Medicine, John Radcliffe Hospital, Oxford, OX3 \\ 9DU, United Kingdom
}

\begin{abstract}
IgM paraproteins associated with autoimmune peripheral neuropathy and anti-Pr cold agglutinins react with sialic acid epitopes present on disialylated gangliosides including GD1b, GT1b, GQ1b, and GD3. A causal relationship between the paraprotein and the neuropathy has never been proven experimentally. From peripheral blood B cells of an affected patient, we have cloned a human hybridoma secreting an antidisialosyl IgM $\mathrm{mAb}$, termed Ha1, that shows identical structural and functional characteristics to its serum counterpart. Variable region analysis shows $\mathrm{Ha} 1$ is encoded by the same $V_{H} 1$ family heavy chain gene, V1-18, as the only other known anti-Pr antibody sequence and is somatically mutated, suggesting that is arose in vivo in response to antigenic stimulation. In the rodent peripheral nervous system, Ha1 immunolocalizes to dorsal root ganglia, motor nerve terminals, muscle spindles, myelinated axons, and nodes of Ranvier. After intraperitoneal injection of affinity-purified antibody into mice for $10 \mathrm{~d}$, electrophysiological recordings from the phrenic nerve-hemidiaphragm preparation demonstrated impairment of nerve excitability and a reduction in quantal release of neurotransmitter. These data unequivocally establish that an antidisialosyl antibody can exert pathophysiological effects on the peripheral nervous system and strongly support the view that the antibody contributes to the associated human disease. ( $J$. Clin. Invest. 1996. 97:1155-1164.) Key words: autoimmunity - monoclonal antibodies - peripheral nerve diseases • neuromuscular junction • electrophysiology
\end{abstract}

\section{Introduction}

Gangliosides comprise a large family of predominantly cell surface glycosphingolipids containing a ceramide moiety anchored in the external leaflet of the lipid bilayer with a sialy-

Address correspondence to Hugh J. Willison, University Department of Neurology, Institute of Neurological Sciences, Southern General Hospital, Glasgow, G51 4TF Scotland. Phone: 41-201-1100 ext. 2464; FAX: 41-201-2993; E-mail: gora13@udcf.gla.ac.uk

Received for publication 11 October 1995 and accepted in revised form 1 December 1995.

J. Clin. Invest.

(C) The American Society for Clinical Investigation, Inc.

0021-9738/96/03/1155/10 \$2.00

Volume 97, Number 5, March 1996, 1155-1164 lated oligosaccharide core exposed extracellularly (1). They are highly enriched in neuronal and glial plasma membranes throughout the nervous system where they are spatially and temporally segregated in well defined patterns and exhibit wide functional diversity (2). Several distinct phenotypes of autoimmune neuropathy are associated with high serum levels of antiganglioside antibodies (3-6). Current evidence suggests that antiganglioside antibodies arise as a result of molecular mimicry with structurally similar bacterial lipopolysaccharides that provide the antigenic stimulation for their production (711). It is assumed that the antibodies induce neuropathy by binding to nerve surface gangliosides and activating proinflammatory pathways or by causing physiological block of ganglioside-modulated peripheral nerve functions. However, direct evidence for a pathological role of antiganglioside antibodies has not yet been obtained and remains highly controversial (12-13).

One form of peripheral neuropathy associated with a specific pattern of antiganglioside antibodies is a chronic IgM paraproteinaemic neuropathy with clinical features including ataxia, areflexia, variable ophthalmoplegia, and cold agglutinin activity (14-21, herein termed CANOMAD, chronic ataxic neuropathy with opthalmoplegia, M-protein, agglutination, and disialosyl antibodies) ${ }^{1}$. In this syndrome, the IgM paraprotein reacts with gangliosides bearing $\mathrm{NeuAc}(\alpha 2-8) \mathrm{NeuAc}(\alpha 2-$ 3)Gal disialosyl epitopes present on GQ1b, GT1a, GT1b, GD1b, GD3, and GD2. In addition to neuropathic features, $50 \%$ of CANOMAD patients also have cold agglutinin disease due to associated red cell cold agglutinating activity of anti-Pr specificity $(21,22)$.

This investigation concerns the pathogenic relationship between antidisialosyl IgM paraproteins and the presence of peripheral neuropathy in CANOMAD patients. We here describe the cloning and sequencing of an $\mathrm{mAb}$ from a hybridoma cell line, derived from PBLs of a patient with CANOMAD, which secretes the antiganglioside paraprotein found in the patient's serum. The mAb and a red blood cell affinity-purified fraction from the patient's serum are identical in ganglioside specificity and isoelectric point. We show that the antibody

1. Abbreviations used in this paper: Btx, $\alpha$-bungarotoxin; CANO$\mathrm{MAD}$, chronic ataxic neuropathy with opthalmoplegia, M-protein, agglutination, and disialosyl antibodies; CDR, complementarity determining region; $\mathrm{Cj}$, campylobacter jejuni; $\mathrm{CT}$, cholera toxin; EPP, endplate potential; IEF, isoelectric focusing; MEPP, miniature endplate potential; MFS, Miller Fisher syndrome; PNS, peripheral nervous system. 
binds to a wide range of peripheral nerve structures and induces electrophysiological abnormalities in mouse nerve compatible with its putative pathophysiological effects on the human peripheral nervous system (PNS). Previous animal studies using antiganglioside antibodies to induce experimental neuropathy using whole sera or partially purified sera (23-32) have also shown immunopathogenic effects. These data lend great support to the view that antiganglioside antibodies have the capacity to induce autoimmune neurological disease.

\section{Methods}

Clinical and serological studies. BMCs were isolated from venous blood by density gradient centrifugation using Nycoprep 1.077 (Nycomed, Oslo, Norway) from patient Ha whose clinical and electrophysiological features have been previously reported in detail. Briefly, Ha is a 67 year old female with a chronic demyelinating peripheral neuropathy comprising severe sensory ataxia, areflexia and mild limb weakness interspersed with acute relapsing episodes of increasing limb weakness and craniobulbar dysfunction (including opthalmoplegia). She has a benign $\operatorname{IgM} \lambda$ monoclonal gammopathy of $6.4 \mathrm{~g} /$ liter with antiganglioside antibody activity (see below) of the CANOMAD pattern. The paraprotein also has cold agglutinating activity typed as anti- $\mathrm{Pr}_{2}$ by standard techniques (22); this activity was first identified at routine cross-matching when Ha was $52 \mathrm{yr}$ old in 1980 and allows one to purify the serum IgM paraprotein on red cells for experimental studies: cold agglutinating antibodies were affinity purified from the serum by temperature-dependent elution on human group $\mathrm{O}$ red blood cells as previously described and this fraction is referred to as rbcM. The antiganglioside activity of the serum was characterized by ELISA as previously described (19) and found to contain exclusively $\operatorname{IgM} \lambda$ antibodies against GD1b (titre of $1 / 850,000$ ), GQ1b (1/450,000), GT1b (1/300,000), GD3 (1/260,000), GM3 (1/660) and GD1a (1/570) with no reactivity against GM1 or GM2. rbcM gave an identical pattern of reactivity. The structure of relevant gangliosides is shown in Table I. All experiments had local ethical committee approval on the use of human material.

Monoclonal antibody production and characterization. Monoclonal antibodies were produced by transformation of $2 \times 10^{7}$ PBMCs with EBV containing supernatant from overgrown cultures of the B95-8 cell line according to previously described techniques $(33,34)$. Cultures were screened for anti-GT1b ganglioside antibody production, and cells from antibody positive wells were pooled and fused using polyethylene glycol with OUR-1 cells, an ouabain resistant subclone of the mouse myeloma cell line X63-Ag8.653 (33). Anti-GT1b antibody positive cells from this fusion were then cloned by repeated rounds of limiting dilution. The antibody was concentrated from tissue culture supernatant and quantitated using standard radial immunodiffusion and immunoassay techniques $(35,36)$. Hybridoma specificity, stability and monoclonality were checked by ELISA, TLC overlay, and isoelectric focusing (IEF) of culture supernatants. TLC overlay was performed as previously described $(19,34)$ using the enhanced chemiluminescence system according to manufacturer's instructions (Amersham International, Little Chalfont, UK). IEF of IgM immunoglobulins was performed in $0.5 \mathrm{~mm}$ agarose gels with a $\mathrm{pH}$ gradient composed of $1 \mathrm{ml}$ Pharmalyte 5-8 and $0.25 \mathrm{ml}$ Pharmalyte $3-10$ using standard apparatus and reagents (Pharmacia Diagnostics, Uppsala, Sweden). IgM was analyzed both in native form and after reduction with $1 \%$ 2-mercaptoethanol for $15 \mathrm{~min}$ before focusing in order to optimize resolution. After focusing, Igs were transferred to nitrocellulose and immunostained with class-specific antibodies using a double antibody method as previously described $(34,37)$.

Variable region gene cloning and sequencing. Total RNA was prepared from $1 \times 10^{7}$ hybridoma cells by the acid guanidinium phenol/ chloroform method (38). $10 \mu \mathrm{g}$ of total RNA was reverse transcribed with M-MLV reverse transcriptase (Gibco BRL, Paisley, Scotland) and antisense primers for mu and lambda $\mathrm{CH} 1$ constant regions. All primers were synthesized by Genosys (Cambridge, UK) using heavy and light chain primer sequences as previously described $(39,40)$. The products of 1st strand cDNA synthesis were directly amplified by PCR using VH1-6 family specific VH leader sequence primers and degenerate primers for the VL leader sequences in conjunction with the constant region primers referred to above. Amplification was performed for 30 cycles in a Perkin Elmer DNA thermal cycler with 100 $\mu \mathrm{l}$ reaction volumes containing 2.5 U TAQ polymerase and buffer (Promega, Southampton, UK) supplemented with $\mathrm{MgCl}_{2}$ at a final concentration of $1.5 \mathrm{mM}$. Each cycle consisted of a denaturation step at $94^{\circ} \mathrm{C}$ for $1 \mathrm{~min}$, an annealing step at $55^{\circ} \mathrm{C}$ for $1 \mathrm{~min}$, and a primer extension step at $72^{\circ} \mathrm{C}$ for $1 \mathrm{~min}$ followed by a final incubation of $72^{\circ} \mathrm{C}$ for $10 \mathrm{~min}$. PCR products were visualized on $2 \%$ agarose gels.

The heavy chain PCR products were cloned directly into the $\mathrm{pCR}^{\mathrm{TM}} \mathrm{II}$ plasmid (Invitrogen, British Biotechnology Products, Abingdon, UK) as per manufacturer's instructions. Single stranded templates for sequencing were produced upon infection of helper phage VCSM13 (Stratagene Inc., La Jolla, CA), and clones derived from two separate PCR amplifications were used for sequencing. The light chains were digested with EcoRI and HindIII and cloned into M13mp18 and 19. The heavy and light chains were sequenced by the dideoxy chain termination method using $\left[{ }^{35} \mathrm{~S}\right] \mathrm{dATP}$ and the Sequenase Version 2.0 DNA sequencing kit (United States Biochemicals, Cleveland, $\mathrm{OH})$. Sequences were analyzed using the software package of the Genetics Computer Group, (1991), Program manual for the GCG Package, Version 8, September 1994, 575 Science Drive, Madison, WI 53711. Identity searches for germline counterparts were performed using the FASTA program with the GenBank and EMBL databases.

Immunohistochemical studies. The binding of the $\mathrm{mAb} \mathrm{Ha} 1$ and rbcM to peripheral nerve structures was examined in sciatic and com-

\section{Table I. Ganglioside Structures}

\begin{tabular}{|c|c|}
\hline Ganglioside & Carbohydrate sequence \\
\hline GQ1b & $\begin{array}{ll}\text { Gal }(\beta 1-3) \text { GalNAc }(\beta 1-4) & \text { Gal }(\beta 1-4) \text { Glc }(\beta 1-1) \text { Ceramide } \\
(\alpha 2-3) & (\alpha 2-3) \\
\text { NeuNAc } & \text { NeuNAc } \\
*(\alpha 2-8) & (\alpha 2-8) \\
\text { NeuNAc } & \text { NeuNAc }\end{array}$ \\
\hline GT1b & $\begin{array}{ll}\text { Gal }(\beta 1-3) \text { GalNAc }(\beta 1-4) & \text { Gal }(\beta 1-4) \text { Glc }(\beta 1-1) \text { Ceramide } \\
(\alpha 2-3) & (\alpha 2-3) \\
\text { NeuNAc } & \text { NeuNac } \\
& (\alpha 2-8) \\
& \text { NeuNAc }\end{array}$ \\
\hline GD1b & $\begin{aligned} \text { Gal }(\beta 1-3) \text { GalNAc }(\beta 1-4) & \text { Gal }(\beta 1-4) \text { Glc }(\beta 1-1) \text { Ceramide } \\
& (\alpha 2-3) \\
& \text { NeuNAc } \\
& (\alpha 2-8) \\
& \text { NeuNAc }\end{aligned}$ \\
\hline GD3 & $\begin{array}{l}\text { Gal }(\beta 1-4) \text { Glc }(\beta 1-1) \text { Ceramide } \\
(\alpha 2-3) \\
\text { NeuNAc } \\
(\alpha 2-8) \\
\text { NeuNAc }\end{array}$ \\
\hline GM1 & $\begin{array}{c}\operatorname{Gal}(\beta 1-3) \operatorname{GalNAc}(\beta 1-4) \operatorname{Gal}(\beta 1-4) \operatorname{Glc}(\beta 1-1) \text { Ceramide } \\
(\alpha 2-3) \\
\text { NeuNAc }\end{array}$ \\
\hline
\end{tabular}

*All gangliosides bearing at least one NeuNAc $(\alpha 2-8)$ NeuNAc structure configured either on the terminal (as shown) or internal galactose residue react with Ha serum, rbcM, and monoclonal antibody. GM1 is not bound. 
mon peroneal nerve and tibialis anterior muscle obtained from freshly killed adult NIH mice and Sprague-Dawley rats. All staining routines were performed in conjunction with human IgM and secondary antibody alone serving as a negative controls. Tissues were snap frozen in isopentane cooled by liquid nitrogen and stored at $-70^{\circ} \mathrm{C}$ before use. Tissue blocks were mounted in O.C.T. compound (Tissue-Tek, Elkhart, Indiana) at $-25^{\circ} \mathrm{C}$ and $5-15 \mu \mathrm{m}$ sections were cut onto 3-aminopropyltriethoxysilane (APES)-coated slides. Teased fibers were prepared from fresh mid-trunk sciatic nerve by desheathing and spreading $0.5-\mathrm{cm}$ lengths onto APES-coated slides using finegauge syringe needles. All immunofluorescence staining was performed at $20 \mu \mathrm{g} / \mathrm{ml}$ of $\mathrm{Ha} 1$ or rbcM. Fluorescein-labeled cholera toxin B subunit (CT), a specific ligand for GM1 ganglioside (41) was purchased from List Biologicals, Campbell, CA. Bodipy-labeled $\alpha$-bungarotoxin (BTx, a ligand for postsynaptic acetylcholine receptors) was purchased from Molecular Probes, Eugene, OR. Fluoresceinand rhodamine-labeled secondary antibody were purchased from Southern Biotechnology Associates, Birmingham, AL. Unfixed tissue sections were incubated overnight in a water vapor-saturated chamber at $4^{\circ} \mathrm{C}$ with $\mathrm{Ha} 1(20 \mu \mathrm{g} / \mathrm{ml})$ in PBS containing $10 \%$ lamb serum and $0.01 \%$ sodium azide. Samples were rinsed in several changes of cold PBS before incubation at $4^{\circ} \mathrm{C}$ with a rhodamine-labeled goat anti-human IgM antiserum (1:200 in PBS). For dual labeling studies, fluorescein-labeled CT $(2 \mu \mathrm{g} / \mathrm{ml})$ or fluorescein-labeled BTx $(1 \mu \mathrm{g} /$ $\mathrm{ml}$ ) were added to the secondary antibody incubation medium. After a final rinse series in cold PBS the tissue sections were mounted in antifade solution (Citifluor, Canterbury, UK) and stored at $4^{\circ} \mathrm{C}$ before viewing. Images were obtained on a Bio-Rad MRC600 confocal microscope (Richmond, CA) fitted with a krypton/argon laser and attached to a Nikon Diaphot fluorescent microscope. In some instances a Z-series of five to seven images was collected through a region of interest, and in others images were contrast enhanced before forming the final figure. Images were printed directly using a photographicquality color printer (ColourEase; Eastman Kodak Co., Rochester, NY).

Passive transfer studies. The ability of the antidisialosyl antibody from patient Ha to induce experimental neuropathy was studied electrophysiologically in the mouse phrenic nerve-hemidiaphragm using a previously described protocol (31). All animal experiments were performed under Home Office (UK) license guidelines. Adult male MF1 mice (18-20 g) were used. Plasma $(1.0 \mathrm{ml} / \mathrm{d})$ or $\mathrm{rbcM}(5 \mathrm{mg} / \mathrm{d})$ was injected intraperitoneally into mice daily for $10 \mathrm{~d}$ and animals were then killed for electrophysiological and morphological examination. Insufficient hybridoma-derived $\mathrm{mAb}$ (Ha1) was available for passive transfer due to the low levels of antibody secreted by human mouse heterohybridomas compared with the amounts available from serum, and therefore both whole plasma (totaling $120 \mathrm{ml}$ ) and rbcM (totaling $200 \mathrm{mg}$ ) were used. In parallel with test animals, control animals were injected with similar amounts of pooled human plasma or human IgM. Human IgM was purified from pooled human plasma or Pentaglobin (Biotest Pharma GmbH, Dreieich, Germany) by euglobulin precipitation with or without further purification on Sephadex 6B gel filtration chromatography (Pharmacia Biotechnology Inc., Piscataway, $\mathrm{NJ}$ ).

Morphological and immunofluorescence studies were performed on the phrenic nerve and hemidiaphragm muscle since this was the site at which electrophysiological observations were made. The phrenic nerve and hemidiaphragm muscle were fixed in phosphatebuffered $4 \%$ paraformaldehyde and processed for light microscopy by standard techniques or processed unfixed for Ig immunofluorescence by snap freezing in isopentane as described above.

Neuronal function was studied in the phrenic nerve-hemidiaphragm preparation using conventional postsynaptic microelectrode techniques $(31,32)$. After $10 \mathrm{~d}$ of passive transfer the phrenic nervehemidiaphragm was freshly dissected and the physiological preparation was perfused with $\mathrm{Krebs}$ solution (in $\mathrm{mM}$ : $\mathrm{NaCl}, 118 ; \mathrm{KCl}, 4.7$; $\mathrm{MgSO}_{4}, 1.2 ; \mathrm{KH}_{2} \mathrm{PO}_{4}, 1.2 ; \mathrm{NaHCO}_{3}, 25 ; \mathrm{CaCl}_{2}, 2.52 ;$ Glucose, 11.1; $\mathrm{pH} 7.3-7.4)$ gassed with $95 \% \mathrm{O}_{2} / 5 \% \mathrm{CO}_{2}$. Microelectrode recordings were performed in a $3 \mathrm{ml}$ bath with constant gassing. The minimal stimulus intensity in volts applied via a suction electrode $(0.1 \mathrm{~ms}$ pulse duration) to evoke a contraction of the whole diaphragm (stimulus threshold) was first measured. $\mu$-conotoxin $(1 \mu \mathrm{M})$ that paralyzes muscle contraction by a selective action on the muscle sodium channels was then added. Neurotransmitter release was studied by recording the small depolarizations resulting from spontaneous transmitter release (miniature endplate potentials, MEPPs), and nerve-evoked neurotransmitter release (endplate potentials, EPPs) in each fiber. The nerve stimulus required to evoke EPPs at each endplate was noted, and the EPPs then measured at supramaximal voltage. Recordings were amplified, filtered at $5 \mathrm{kHz}$ and saved to disk for subsequent off-line analysis (SCAN software, University of Strathclyde, Scotland). All recordings were made at room temperature $\left(18-20^{\circ} \mathrm{C}\right)$. In individual preparations, 20-50 MEPPs and EPPs were recorded from each of $10-15$ endplates.

\section{Results}

Characteristics of the $\mathrm{mAb} \mathrm{Hal}$ and identity of Hal to the serum paraprotein and the affinity purified $r b c M$

Screening of supernatants from $4 \times 10^{7}$ EBV-transformed PBMCs against GT1b ganglioside yielded positive colonies in 82 of 192 wells suggesting that the frequency of circulating B cells secreting the paraprotein was high. Pooled cells from these wells were fused and six positive wells from the fusion were subcloned to monoclonality. These clones were found to be isoelectrically identical on IEF. One of these, hereafter termed Ha1, was selected for further study. Ha1 was typed as an $\operatorname{IgM} \lambda$ antibody (as were both the serum paraprotein and $\mathrm{rbcM}$ ) and bound to the disialylated gangliosides GD1b, GD3, GT1b, and GQ1b which all contain a NeuAc $(\alpha 2-8) \operatorname{NeuAc}(\alpha 2-$ 3)Gal-epitope (Table I) and weakly to GM3 and GD1a which

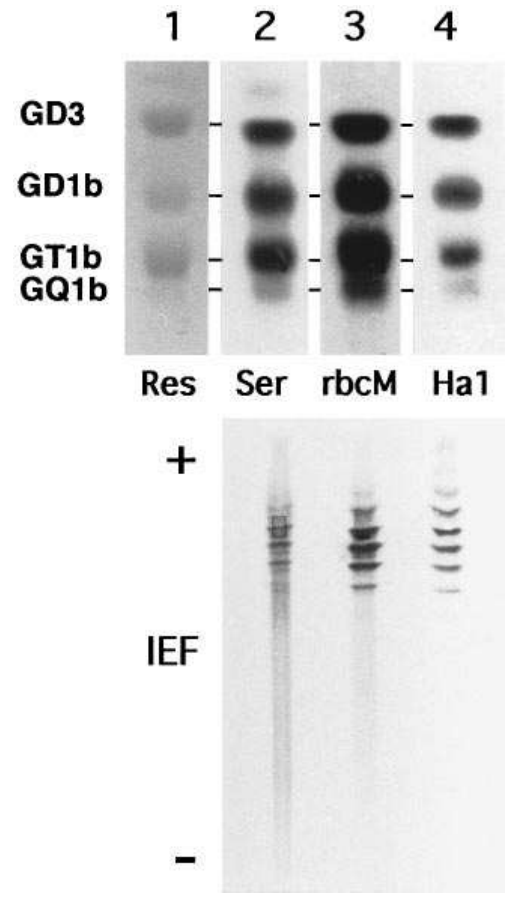

Figure 1. Gangliosides GD3, GD1b, GT1b, and GQ1b were separated by TLC (top) then visualized by resorcinol staining (Res, lane 1$)$ or immunostained by overlaying with Ha's serum (Ser, diluted $1 / 10^{3}$; lane 2), red blood cell affinity purified serum fraction (rbcM, $10 \mu \mathrm{g} / \mathrm{ml}$; lane 3 ) and monoclonal antibody (Ha1 $0.5 \mu \mathrm{g} / \mathrm{ml}$; lane 4) followed by probing with peroxidaselabeled anti-human IgM and autoradiographic detection using enhanced chemiluminescence. Identical patterns of ganglioside reactivity are seen. The corresponding antibody fractions (Ser, $0.05 \mu \mathrm{l}$; rbcM, $25 \mathrm{ng}$; Ha1, 12 ng) were separated by IEF (bottom),

then blotted to nitrocellulose, probed with peroxidase-labeled antihuman IgM and visualized with ethylamino carbazole substrate. The serum contains a background smear of polyclonal IgM and a monoclonal IgM antibody (visible as a ladder) which has isoelectric identity to the ladders present in the rbcM and the cloned antibody, Ha1. +/refer to acidic/basic ends of IEF gel, $\mathrm{pH}$ range 3-10. 


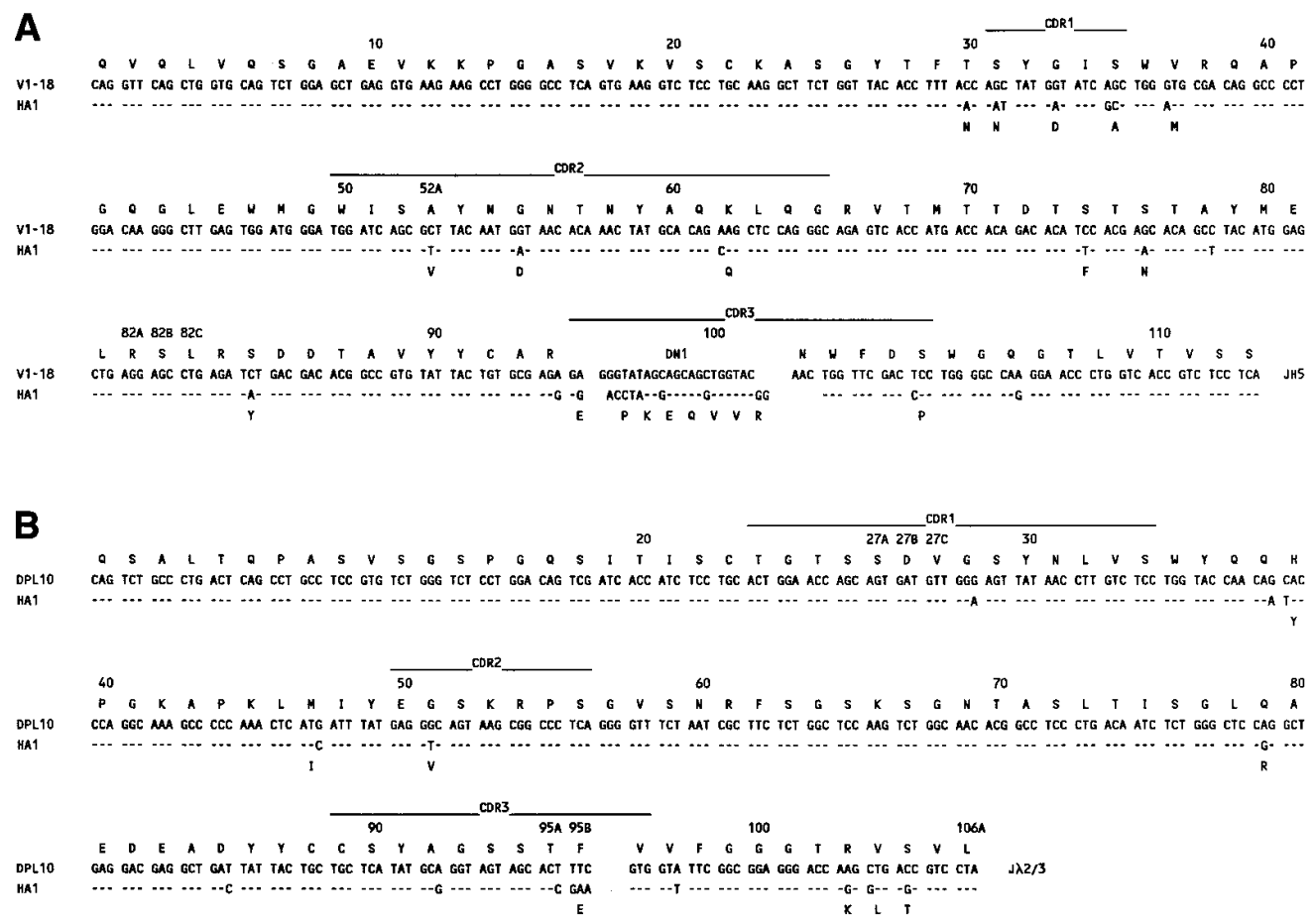

Figure 2. $\mathrm{V}_{\mathrm{H}}$ region $(A)$ and $\mathrm{V}_{\mathrm{L}}$ region $(B)$ sequences of the $\mathrm{mAb}$ Ha1 aligned with their assigned germline counterparts, V1-18 and DPL10. All replacement and silent nucleotide substitutions are marked, with corresponding amino acid changes recorded where present. Both $\mathrm{V}_{\mathrm{H}}$ and $\mathrm{V}_{\mathrm{L}}$ regions show evidence of somatic mutation, particularly clustered in $\mathrm{V}_{\mathrm{H}}$ CDR1 and CDR3. GenBank accession numbers: $\mathrm{V}_{\mathrm{H}}$, X91804; $\mathrm{V}_{\mathrm{L}}, \mathrm{X} 91805$. contain a terminal NeuAc( $\alpha 2-3)$ Gal-epitope, but did not bind to structurally dissimilar glycolipids including GM1, GM2, globoside, and sulphatide (data not shown). This gangliosidebinding profile was identical to that seen on ELISA of Ha's serum and rbcM. The ganglioside-binding profiles are shown by TLC-overlay (Fig. 1, top).

Ha1 binding to gangliosides was shown to be highly temperature dependent, being greater at $4^{\circ} \mathrm{C}$ than at $20^{\circ} \mathrm{C}$ (room temperature) or $37^{\circ} \mathrm{C}$ (body temperature), as previously noted for the serum and rbcM (19). In addition, Ha1 agglutinated human red blood cells in the cold $\left(4^{\circ} \mathrm{C}\right)$ with a hemagglutination titre (as expressed in milligrams of IgM) identical to that of the rbc-M fraction (data not shown).

To establish that the cloned antibody corresponded to the major paraprotein present in the serum and the rbcM rather than an irrelevant antibody, the three preparations were examined by IEF (Fig. 1, bottom). In IEF gels, monoclonal Igs resolve as ladders comprising several evenly spaced bands as a result of charge microheterogeneity. All three preparations (Ha1, rbcM, and serum) contained a dominant banding pattern that migrated to an identical position in the IEF gels, indicating isoelectric identity and by inference, structural identity. From these data (heavy and light chain class, ganglioside specificity, thermal range, heamagglutination properties, and isoelectric point) we concluded that $\mathrm{Ha} 1$ is the antibody that accounts for the ganglioside-binding IgM paraprotein in Ha's serum and is the major component of the red blood cell-purified $\operatorname{IgM}(\mathrm{rbcM})$.

\section{Immunoglobulin heavy and light chain variable region gene usage}

Sequence analysis showed that the Ha1 antibody was encoded by $\mathrm{V}_{\mathrm{H}} 1$ and $\mathrm{V}_{\lambda} 2$ variable region family members (Fig. 2). The $\mathrm{Ha} 1 \mathrm{~V}_{\mathrm{H}}$ region showed a $94.6 \%$ nucleotide identity to the $\mathrm{V}_{\mathrm{H}} 1$ gene segment V1-18 (42). The complementarity determining region 3 (CDR3) is 12 amino acids in size with the $\mathrm{D}$ region showing the greatest similarity to DN1 and the $\mathrm{J}$ region being $\mathrm{J}_{\mathrm{H}}$ 5. The $\mathrm{V}_{\lambda}$ region showed a $96 \%$ nucleotide identity to the $\mathrm{V}_{\lambda} 2$ gene segment DPL10 (43) with the $\mathrm{J}_{\lambda} 2 / 3$ segment making up the rest of the variable region. Both heavy and light chain variable regions show evidence of somatic mutation, predominantly within CDR1 and CDR3 of the heavy chain.

\section{Patterns of tissue binding of the $m A b, H a 1$ in the rodent peripheral nervous system}

Ha1 bound to a wide array of structures in the rodent PNS, including dorsal root ganglia, peripheral nerve axonal profiles, compact myelin, nodes of Ranvier, motor end plates, and muscle spindles. Ha1 gave identical staining patterns to rbcM, consistent with their identity as demonstrated above. In both rat and mouse dorsal root ganglia, Ha1 stained the plasma membrane and cytoplasm of neurons. Occasional cells displayed much stronger binding and dual-labeling studies indicated that such cells were often also strongly CT positive, cholera toxin being a specific ligand for GM1 ganglioside. Staining of nerve fibers in transverse section was similar within dorsal root ganglia nerve fiber bundles, spinal roots, nerve trunk, and intramuscular nerve. In dual-labeling studies with CT, Ha1 staining extended into the axonal lumen of myelinated nerve fibers. In teased fibers from mouse sciatic nerve, Ha1-labeled compact myelin exposed at points of damage, created during the teasing process, and labeled axons protruding beyond ruptured myelin sheaths (Fig. 3, row $a$ ). Ha1 also labeled nodes of Ranvier in some intact teased fibers (Fig. 3, row $b$ ). In the rat, nodal staining was less frequently observed. In both mouse and rat, Ha1 strongly labeled capillaries within the nerve bundle. In the rat muscle spindle, Ha1 bound strongly to a region immediately adjacent to the intrafusal fibers, corresponding to the area defined by the internal capsule. In co-labeling studies with CT, both ligands bound to myelinated nerve bundles associated with spindles and to structures thought to be sensory nerve terminals closely apposed to the intrafusal fiber surface (Fig. 3, 

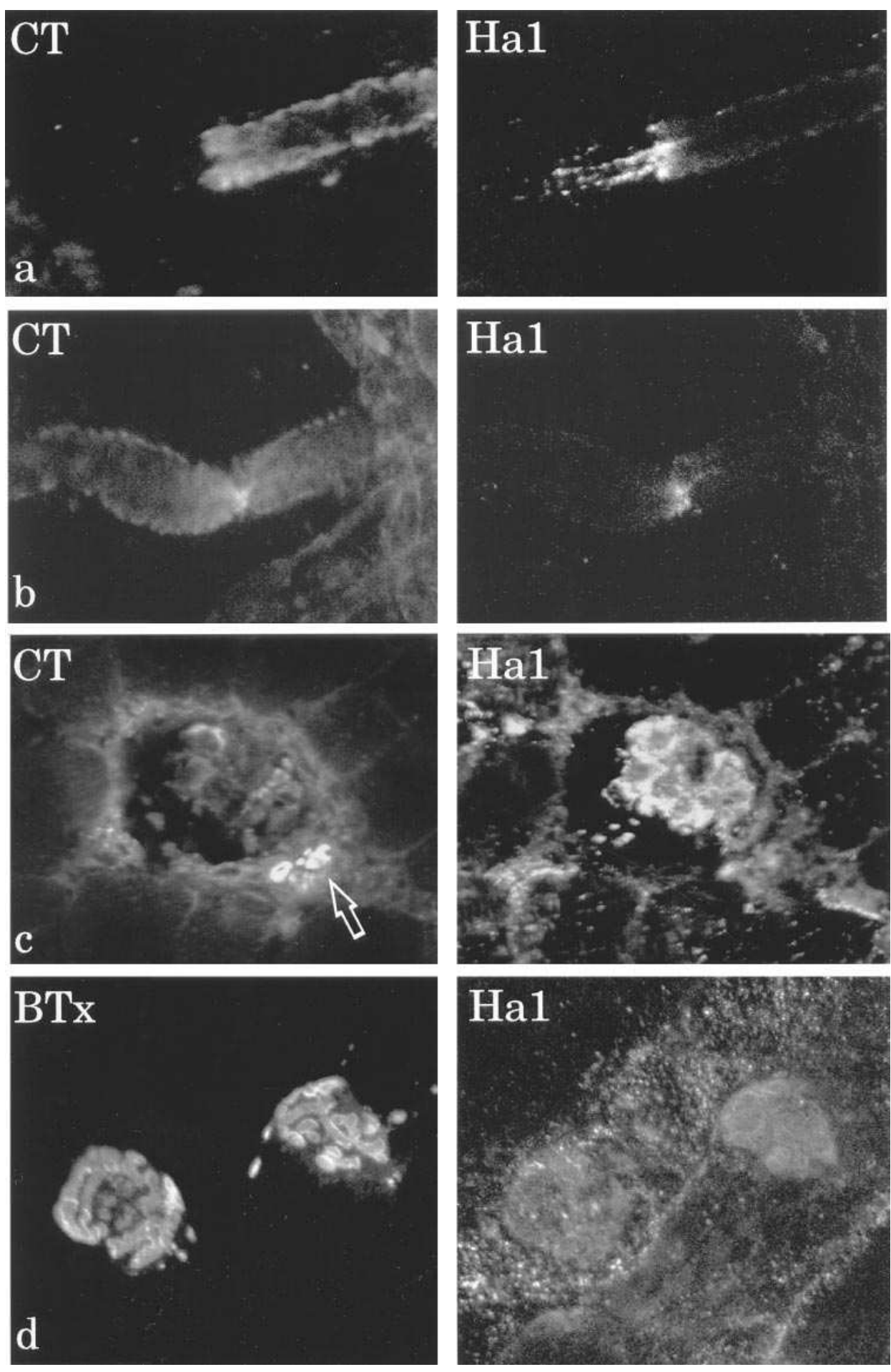

Figure 3. Immunolocalization of $\mathrm{Ha} 1$ in peripheral nerve structures colabeled with cholera toxin B subunit $(C T$, a specific ligand for GM1 ganglioside; rows $a-c$ ) or $\alpha$-bungarotoxin (BTx, a specific ligand for postsynaptic acetylcholine receptors; row $d$ ) Row $a$ shows Ha1 labeling of an axon protruding from a myelinated nerve fiber ruptured during teasing and outline by CT. Row $b$ shows Ha1 staining at the node of Ranvier in a teased fiber outlined by CT. Row $c$ shows Ha1 staining of intrafusal muscle fibers in a transverse section through a muscle spindle and staining of the adjacent capsule and muscle membranes. Ha1 also stains the nerve supply of the spindle which is also intensely stained by CT (arrow). Row $d$ shows diffuse Ha1 localization at motor end plate regions costained with BTx and speckled Ha1 staining of adjacent muscle membranes. row $c$ ). Ha1 also bound in the region of the neuromuscular junction in both mouse and rat muscle, as demonstrated by colocalization of Ha1 with BTx, a specific ligand for postsynaptic acetyl choline receptors (Fig. 3, row $d$ ).

\section{Passive transfer studies}

In pilot studies (not shown), groups of two animals were injected with Ha's plasma for durations up to $21 \mathrm{~d}$; near maximal electrophysiological effects were observed by $10 \mathrm{~d}$ and this time point was thus selected for further study. Two animals each were injected with Ha's plasma, Ha's rbcM, pooled normal plasma, and pooled normal $\mathrm{IgM}$. In two animals injected for $10 \mathrm{~d}$ with $5 \mathrm{mg} / \mathrm{d}$ of rbcM, the human IgM concentrations in mouse sera were 1.35 and $1.10 \mathrm{mg} / \mathrm{ml}$ with corresponding antiGT1b antibody titres of $1 / 3,500$ and $1 / 1,700$, respectively; these animals were used for direct immunofluorescence studies (see below). No animals had any weight loss or showed clinical signs of neurological disease.

Morphology and immunohistochemistry. Sciatic nerve and phrenic nerve hemidiaphragm tissue from the animals injected with rbcM were morphologically normal at the light micro- 

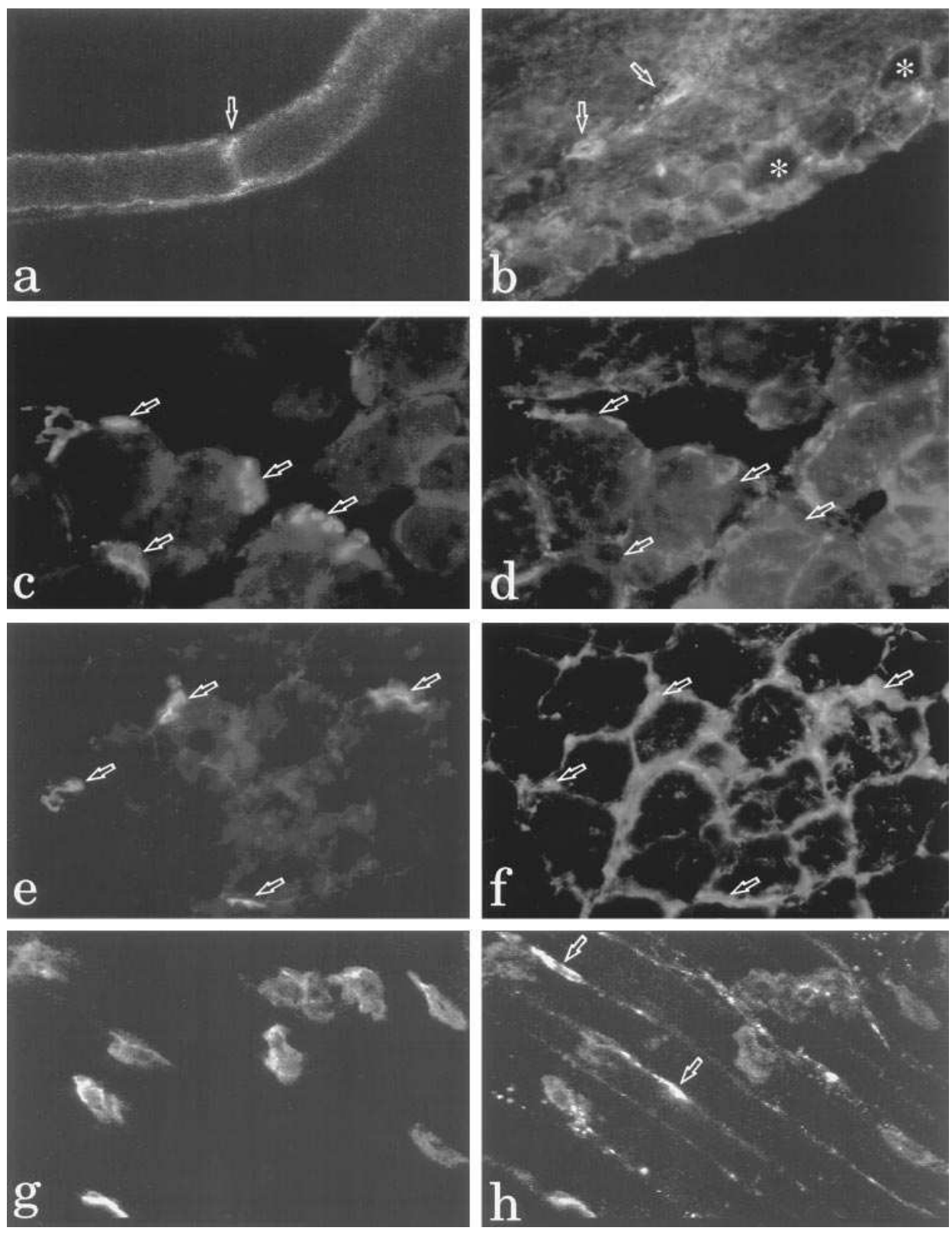

Figure 4. Immunolocalization of rbcM and normal IgM in peripheral nerve after passive transfer, identified with fluoresceinated anti-human IgM $(a-h)$ and dual labeled with BTx $(c, e$, $g$ ). (a) teased fiber from rbcM-treated mouse mid-sciatic nerve stained with anti-human IgM showing IgM deposition at a node of Ranvier (arrow) and along the outer surface of the myelinated fiber; $(b)$ transverse section of normal IgM treated mouse dorsal root ganglion showing IgM in blood vessels (arrows) and around neuronal cell bodies (asterisks). Similar appearances were seen with both rbcM and normal IgM in these two sites $(a$ and $b)$. In transverse sections of tibialis anterior muscle $(c-f)$ dual labeled with $\mathrm{BTx}$ ( $c$ and $e$ ) to show motor end plates (arrows) both normal $\operatorname{IgM}(d)$ and rbcM $(f)$ were widespread in the interstitial compartment adjacent to muscle membranes and in addition, rbcM but not normal IgM appeared selectively concentrated over motor end plates (arrows in $c-f$ ). In whole mount preparations of $\mathrm{rbcM}$ treated mouse hemidiaphragm colabeled with BTx $(g)$ and anti-human $\operatorname{IgM}(h)$ rbcM was seen in blood vessels (arrows), in interstitial spaces, and was specifically concentrated over motor end plate regions.

scope level when compared to similarly fixed controls (data not shown). In addition, animals injected with rbcM and normal human IgM were examined for evidence of human IgM deposition within all areas of the PNS and found to show very similar patterns (Fig. 4). IgM was observed in many sites including blood vessels, interstitial spaces, motor end plate regions, nodes of Ranvier, and around neuronal cell bodies in the dorsal root ganglia. Taking account of the widespread presence of both control IgM and rbcM within extracellular spaces in muscle, there was qualitatively more IgM concentrated at the neuromuscular junction in rbcM-injected mice compared with control IgM-injected mice (Fig. 4, $c-h$ ).

Electrophysiology. Results in diaphragms from animals injected with control human plasma and IgM showed no differences from size-matched untreated preparations. With both Ha's plasma and rbcM very similar changes were found (Table II). Firstly, there was an increase in the stimulus threshold for nerve-evoked muscle contraction in Ha plasma-treated (means of 2.6 and $4.5 \mathrm{~V}$ ) and in rbcM-treated mice (means of 6 and
$7.5 \mathrm{~V}$ ) compared to control plasma-treated (means of 0.8 and $1.4 \mathrm{~V}$ ) and control IgM-treated mice (means of 1.2 and $1.0 \mathrm{~V}$ ). After paralysis of muscle contraction with $\mu$-conotoxin, the stimulus threshold for nerve-evoked EPPs at individual endplates was increased from $<2 \mathrm{~V}$ in control animals to between 3 and $9 \mathrm{~V}$ in animals treated with Ha preparations. Moreover, the amplitude of the EPPs, even at supramaximal stimuli, was markedly reduced without any change in MEPP amplitudes (Fig. 5), indicating a reduction in the quantal release of neurotransmitter. Thus the quantal content of the EPP, which is derived from the EPP and MEPP amplitudes, was also markedly reduced. The spontaneous release, indicated by MEPP frequency, was also significantly reduced. The results are summarized in Table II.

\section{Discussion}

We have cloned and characterized the major serum autoantibody from a patient with the IgM paraproteinaemic neuropa- 
Table II. Electrophysiology of Neuromuscular Transmission in Phrenic Nerve Hemidiaphragm Preparations after $10 \mathrm{~d}$ Passive Transfer of Antiganglioside and Control Plasma and IgM Antibodies to MF1 Mice

\begin{tabular}{|c|c|c|c|c|c|}
\hline & \multicolumn{2}{|c|}{ Spontaneous } & \multicolumn{3}{|c|}{ Nerve-evoked } \\
\hline & MEPP amp* & MEPP freq & Stim thresh ${ }^{ \pm}$ & EPP amp* & Quantal content ${ }^{\S}$ \\
\hline & $m V$ & pers & V & $m V$ & \\
\hline Ha's plasma & $0.98 \pm 0.03^{\|}$ & $0.42 \pm 0.05$ & $6.9 \pm 0.02$ & $9.1 \pm 0.42$ & $10.5 \pm 0.46$ \\
\hline Normal plasma & $0.92 \pm 0.05$ & $0.76 \pm 0.08$ & $1.7 \pm 0.06$ & $17.1 \pm 1.1$ & $26.1 \pm 2.4$ \\
\hline Ha's rbcM & $0.90 \pm 0.04$ & $0.41 \pm 0.04$ & $4.3 \pm 0.17$ & $8.8 \pm 0.9$ & $12.1 \pm 1.2$ \\
\hline Normal IgM & $0.90 \pm 0.04$ & $0.80 \pm 0.06$ & $1.3 \pm 0.05$ & $23.4 \pm 1.2$ & $36.5 \pm 1.8$ \\
\hline
\end{tabular}

*Corrected to a membrane potential of $-80 \mathrm{mV}$; not corrected for nonlinear summation; ${ }^{*}$ nerve stimulus required to evoke an EPP at individual endplates; ${ }^{\S}$ derived by the "direct method" i.e., EPP amplitude corrected for nonlinear summation/MEPP amplitude; "all results are expressed as the mean \pm SEM of data from 20 to 32 endplates examined in two treated animals. MEPP amplitudes showed no significant differences between control and Ha treated animals. All other measures showed highly significant differences ( $p$ values all $<0.001$ ).

thy termed CANOMAD and demonstrated that a highly purified preparation of this antibody binds selectively to neuronal structures and exerts pathophysiological effects in the mouse PNS. This study experimentally confirms that the IgM paraprotein is likely to be a primary cause of this syndrome.

The term IgM paraproteinaemic neuropathy encompasses a clinically and serologically heterogeneous group of conditions. A widely studied subtype is the demyelinating sensorimotor neuropathy associated with antimyelin-associated glycoprotein (anti-MAG) activity; substantial evidence indicates that the anti-MAG antibody is also the cause of its associated syndrome (23-26) although this has never been demonstrated with highly purified or cloned antibodies, as we have done in this study. On the basis of these data, it would seem highly likely that there is also a causal relationship between other IgM paraproteinaemic neuropathies and their monoclonal antiganglioside antibodies.

Ha1 binds to disialosyl gangliosides and to the $\operatorname{Pr}_{2}$ antigen on red blood cells, a cross reactivity first recognized many years ago (44). The variable regions encoding $\mathrm{Ha} 1$ are $\mathrm{V}_{\mathrm{H}} 1$ and $V_{\lambda} 2$ family members and show clear evidence of mutation from their associated germline sequences within heavy and light chain CDRs, suggesting that this antibody has undergone antigen-driven somatic mutation. The only other recorded $\mathrm{V}_{\mathrm{H}}$ sequence encoding an anti- $\mathrm{Pr}_{2}$ antibody from a patient with autoimmune hemolytic anaemia makes use of the VH1GRR germline $\mathrm{V}_{\mathrm{H}}$ gene segment (45); the light chain gene in that study was not sequenced. This partially sequenced VH1GRR germline fragment was shown subsequently to be identical to full-length V1-18/DP14 segments $(42,26)$. Although the overall pattern of somatic mutation observed in the two antibodies differs, they share an alanine to valine substitution at position 52A (47, Kabat and Wu numbering) within the CDR2, suggesting that this residue may be one of those involved in antibody antigen interactions. The high degree of somatic mutation in Ha1 is similar to that recently reported in anti-GM1 IgM antibodies from motor neuropathy cases (48) and provide further data to counter the long held view that IgM antibodies are generally encoded in germline configuration.

Only about $50 \%$ of patients with CANOMAD have IgM cold agglutinating activity with anti- $\mathrm{Pr}_{1}$ or anti- $\mathrm{Pr}_{2}$ specificity, despite the IgM paraproteins from all patients studied having almost identical ganglioside-binding profiles. Conversely, not all anti- $\operatorname{Pr}_{1}$ or anti- $\operatorname{Pr}_{2}$ sera identified in patients with cold ag- glutinin disease have ganglioside binding activity (21) and such patients may be free from peripheral neuropathy. Either the precise structures of the oligosaccharide epitopes on red blood cell glycoconjugates differ from the ganglioside structures, or adjacent molecules influence the ability of antibodies to bind through steric hindrance. The repertoire of $\mathrm{V}_{\mathrm{H}}$ segments used in disease-associated antibodies against another red cell carbohydrate antigen, the $\mathrm{i} / \mathrm{l}$ antigen, is highly restricted to the $\mathrm{V}_{\mathrm{H}} 4$ 21 gene (49-41) although antibodies using other $V_{H}$ families have also been shown to bind to $\mathrm{i} / \mathrm{l}$ antigens in vitro (52). The use of V1-18 by Ha1 may be the first tentative evidence that a similar restriction of $\mathrm{V}_{\mathrm{H}}$ usage as observed with anti-i/l antibodies may also exist for anti- $\mathrm{Pr}_{2}$ antibodies.

The specificity of sera from CANOMAD patients and the mAb Ha1 for NeuAc $(\alpha 2-8) \mathrm{NeuAc}(\alpha 2-3) \mathrm{Gal}$ disialosyl epitopes is very similar to the anti-ganglioside specifities seen in serum from patients with the Miller Fisher variant of Guillain Barré syndrome (MFS, the clinical triad of ataxia, areflexia, and opthalmoplegia). MFS is an acute postinfectious autoimmune neuropathy which may follow Campylobacter jejuni (Cj) infection. MFS bears a strong clinical resemblance to the phenotype seen in the CANOMAD and over $95 \%$ of MFS cases have IgG antibodies to epitopes present on GQ1b and GT1a and other $\mathrm{NeuAc}(\alpha 2-8) \mathrm{NeuAc}(\alpha 2-3) \mathrm{Gal}$ configured gangliosides including GD1b, GT1b, and GD3 (53-55). It has previously been shown that both the anti-GQ1b antibodies in MFS sera and anti-GM1 antibodies in GBS sera react with carbohydrate epitopes on $\mathrm{Cj}$ LPS, and the model proposed for the illness is thus one of molecular mimicry in which the humoral immune response to Cj LPS fortuitously cross-reacts with neural ganglioside antigens, thereby inducing the neuropathy (7-11). It is possible that antidisialosyl IgM antibodies that occur in CANOMAD patients also arise as a result of an immune response primarily generated towards bacterial LPS, in the same way that IgM anti-GM1 antibodies from motor neuropathy patients have been shown to react with $\mathrm{Cj}$ LPS. We suggest that the responsible antigen may be bacterial LPS chronically sequestered in the gastrointestinal tract which could provide a chronic, low level, T-independent antigenic stimulation; this is in contrast to the acute $\mathrm{Cj}$ enteritis which may precipitate acute phase IgG anti-GQ1b or anti-GM1 antibodies and their associated acute illnesses, MFS and GBS, respectively.

Our immunofluorescence studies with $\mathrm{Ha} 1$ demonstrate the widespread presence of reactive antigens in the PNS, sug- 
A 15

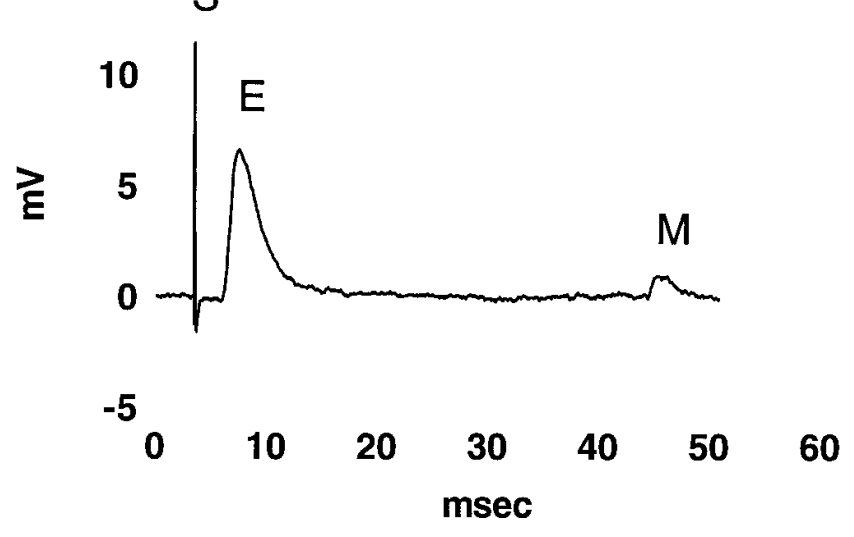

B

40

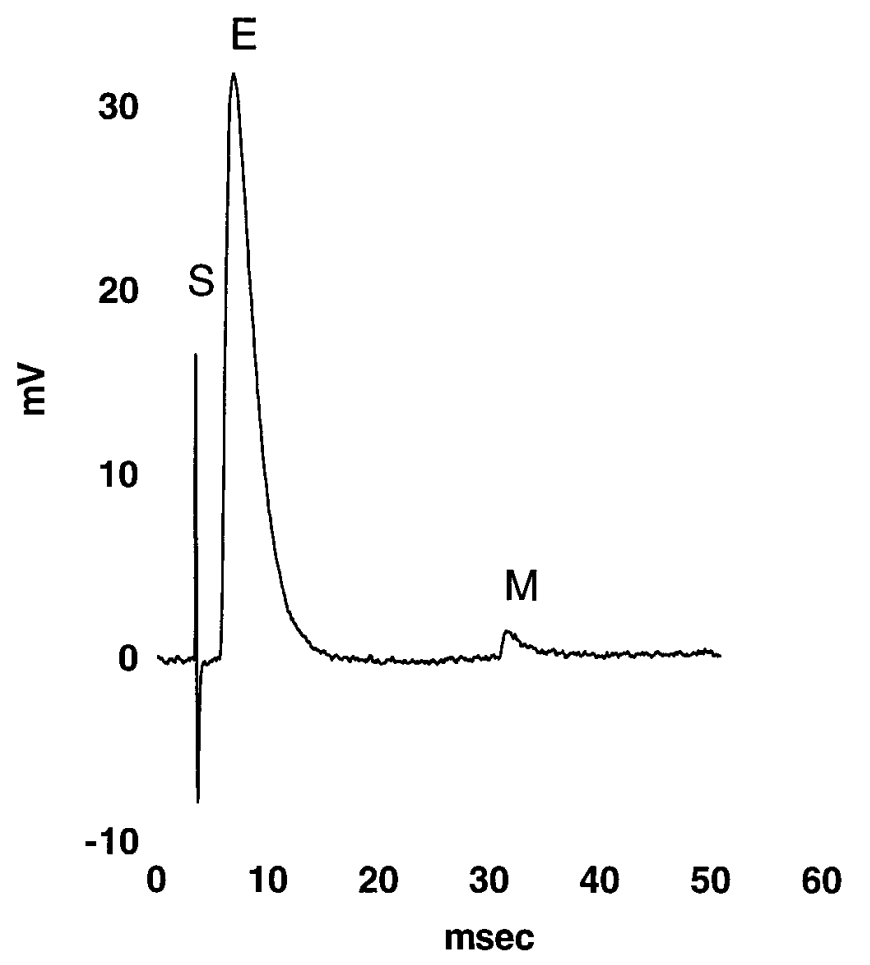

Figure 5. Microelectrode recordings from the hemidiaphragms of an rbcM-treated mouse $(A)$ and of a control IgM treated mouse $(B)$. The $\operatorname{EPP}(E)$ follows the stimulus artifact $(S)$. Spontaneous MEPPS $(M)$ can also be seen. The EPP amplitude is reduced in $A$ compared to that in $B$, but the MEPP amplitudes are similar, indicating that it the quantal content (i.e., the number of packets of neurotransmitter released per nerve impulse) that is affected by the rbcM preparation.

gesting that there may be many sites at which the antibody could exert a pathophysiological effect, were it able to gain access. Access to the PNS by antibody is relatively restricted by the presence of a blood nerve barrier except in dorsal root ganglia and motor nerve terminals where the barrier is deficient. Thus the clinical expression of the disease may be dic- tated by factors other than simply the distribution of antigen. One major factor that might be expected to limit the in vivo tissue binding of Ha's antidisialosyl antibody is the large (several orders of magnitude) reduction in binding at $37^{\circ} \mathrm{C}$ compared with lower temperatures. This might restrict the severity of the human disease; the patient Ha has been affected by this neuropathy for over 15 years without regular therapy and retains reasonable functional capacity and other reported cases often have similarly long histories.

There are several reasons for our use of the phrenic nerve hemidiaphragm preparation in this work. Firstly, our immunolocalization studies indicated the motor nerve terminal to be antigen rich and thus a good candidate site for pathophysiological effects. Secondly, the unmyelinated portion of the distal motor nerve and the neuromuscular junction are outside the blood nerve barrier. Thirdly, the preparation has been successfully used to study other antibody-mediated peripheral nerve diseases $(31,32)$. Fourthly, using this approach one can assess the conduction in individual nerves by measuring spontaneous and evoked neurotransmitter release at individual neuromuscular junctions. Fifthly, even though the patient Ha's symptoms were predominantly sensory rather than motor, clinical neurophysiological assessment indicated that nerve conduction was markedly reduced in motor nerves (19). Although justifying our use of a motor preparation, we recognize the important need in future work to extend our physiological studies to include sensory nerve preparations to draw more clinically relevant pathophysiological conclusions. In the passive transfer studies, we observed the presence of $\operatorname{IgM}$ in dorsal root ganglia and nerve terminal regions and, to a lesser extent, within the endoneural compartment itself after a time period of only $10 \mathrm{~d}$, indicating that $\operatorname{IgM}$ can penetrate to these sites readily. Once within the extracellular environment adjacent to antigen-bearing membranes, it is likely that Ha's antibody would bind antigen. Indeed, some evidence for specific binding to the neuromuscular junction was observed although it was not possible to quantitate this. We found clear evidence of a pathophysiological effect of the antidisialosyl antibody. The stimulus required for nerve-evoked muscle contraction and that for generation of an EPP were substantially raised, suggesting a reduction in nerve excitability occurring somewhere between the site of the stimulus and the motor nerve ending. In addition, the EPPs were reduced in amplitude and the MEPPs were reduced in frequency, suggesting a possible effect on the release of the neurotransmitter, as previously proposed in studies on the acute effects of anti-GQ1b antibody-positive MFS sera (32). Thus, the antibodies appear to affect spontaneous and nerve-evoked neurotransmitter release as well as nerve excitability. The results are partially different from those found in diaphragms of mice treated with IgM antiGM1 antibody positive sera from multifocal motor neuropathy patients, in which the major finding was complete absence of nerve-evoked EPPs at 20-30\% of endplates, with less effect on transmitter release (31).

The lack of major pathological abnormalities at the light microscope level in nerves after passive transfer suggest that the electrophysiological abnormalities are not the result of gross morphological disturbance and could thus represent a physiological rather than proinflammatory effect of Ha's antibody. Binding of IgM could result in complement fixation and a complement-dependent effect of antiganglioside antibodies on neuronal sodium channels has been suggested for anti- 
GM1 antibodies (56). A similar effect of antidiasolysyl antibodies might be responsible for the changes in neuronal excitability described here. However, gangliosides are intimately involved in modulating nerve and synaptic transmission in a wide variety of systems. Botulinum and tetanus toxins, which gain access to the nervous system at motor nerve terminals, include polysialylated gangliosides as part of their ecto-acceptors $(57,58)$. Thus, in addition to more proximal effects, the antidiasolysyl antibody may be interfering with neurotransmitter release via direct binding to and cross-linking of these membrane gangliosides in the absence of an inflammatory cascade. More detailed studies will be required to identify precisely the functional target(s) for the antibody.

\section{Acknowledgments}

We are grateful to the Department of Neuropathology and Professor David Graham, Institute of Neurological Sciences, Glasgow for processing tissues and reviewing the light microscopy and to Beatson Laboratories, Glasgow, for the use of confocal microscope facilities. Professor Peter Behan, University of Glasgow, kindly made the clinical referral.

This work was supported by grants from the Guillain Barré Support Group of Great Britain, The Brims and Halliday Bequests and the Muscular Dystrophy Association. H.J. Willison is a Wellcome Trust Senior Research Fellow in Clinical Science.

\section{References}

1. Ledeen, R.W. 1989. Biosynthesis, metabolism and biological effects of gangliosides. In Neurobiology of Glycoconjugates. R.U. Margolis and R.K. Margolis, editors. Plenum Press, New York. 43-83.

2. Tettemanti, G., and L. Riboni. 1993. Gangliosides and modulation of function of neural cells. Adv. Lipid Res. 25:235-267.

3. Willison, H.J. 1994. Antiglycolipid antibodies in peripheral neuropathy: fact or fiction? J. Neurol. Neurosurg. Psychiatry. 57:1303-1307.

4. Latov, N. 1995. Pathogenesis and therapy of neuropathies associated with monoclonal gammopathies. Ann. Neurol. 37:32-42.

5. O'Leary, C.O., and H.J. Willison. 1995. Immunological investigation. Curr. Opin. Neurol. 8:349-353.

6. Hartung, H.P., J.D. Pollard, G.K. Harvey, and K.V. Toyka. 1995. Immunopathogenesis and treatment of the Guillain-Barré Syndrome. Muscle \& Nerve. 18:137-164.

7. Yuki, N., T. Taki, F. Inagaki, T. Kasama, M. Takahashi, K. Saito, T. Miyataki, and S. Handa. 1993. A bacterium lipopolysaccharide that elicits Guillain-Barré syndrome has a GM1 ganglioside-like structure. J. Exp. Med. 178: 1771-1775.

8. Yuki, N., T. Taki, M. Takahashi, K. Saito, H. Yoshino, T. Tai, S. Handa, and T. Miyatake. 1994. Molecular mimicry between GQ1b ganglioside and liposaccharides of Campylobacter jejuni isolated from patients with Fisher's syndrome. Ann. Neurol. 36:791-793.

9. Jacobs, B.C., H. Endtz, F.G. Van Der Meche, M.P. Hazenberg, H.A. Achtereekte, and P.A. Van Doorn. 1995. Serum anti-GQ1b antibodies recognize surface epitopes on Campylobacter jejuni from patients with Miller Fisher syndrome. Ann. Neurol. 37:260-264.

10. Yuki, N., T. Taki, M. Takahashi, T. Saito, T. Tai, T. Miyatake, and S. Handa. 1994. Penner's serotype 4 of Campylobacter jejuni has a liposaccharide that bears a GM1 epitope as well as one that bears a GD1a epitope. Infect. Immun. 62:2101-2103.

11. Wirguin, I., L. Surturkova-Milsevic, P. Della-Latta, T. Fisher, R.H.J. Brown, and N. Latov. 1994. Monoclonal IgM antibodies to GM1 and asialoGM1 in chronic neuropathies cross-react with Campylobacter jejuni liposaccharides. Ann. Neurol. 35:698-703.

12. Griffin, J.W. 1994. Antiglycolipid antibodies and peripheral neuropathies: links to pathogenesis. Prog. Brain Res. 101:313-326.

13. Parry, G.J.G. 1994. Anti-ganglioside antibodies do not necessarily play a role in multifocal motor neuropathy. Muscle \& Nerve. 17:97-99.

14. Ilyas, A.A., R.H. Quarles, M.C. Dalakas, P.H. Fishman, and R.O. Brady. 1985. Monoclonal IgM in a patient with paraproteineamic polyneuropathy binds to gangliosides containing disialosyl groups. Ann. Neurol. 18:655-659.

15. Duane, G.C., R.G. Farrer, M.C. Dalakas, and R.H. Quarles. 1992. Sensory neuropathy with monoclonal immunoglobulin M to GD1b ganglioside. Ann. Neurol. 31:683-685.
16. Arai, M., H. Yoshino, Y. Kusano, Y. Yasaki, Y. Ohnishi, and T. Miyatake. 1992. Ataxic polyneuropathy and anti- $\operatorname{Pr}_{2} \operatorname{IgM\kappa }$ M proteinaemia. J. Neurol. 239: $147-151$.

17. Obi, T., S. Kusunoki, M. Takatsu, K. Mizoguchi, and Y. Nishimura. 1992. IgM M-protein in a patient with sensory-dominant neuropathy binds preferentially to polysialogangliosides. Acta Neurol. Scand. 86:215-218.

18. Yuki, N., N. Miyatani, S. Sato, Y. Hirabayashi, M. Yamazaki, N. Yoshimura, Y. Hayashi, and T. Miyatake. 1992. Acute relapsing sensory neuropathy associated with $\mathrm{IgM}$ antibody against B-series gangliosides containing a GalNAc $\beta 1-4($ Gal3-2 $\alpha$ NeuAc8-2 $\alpha$ NeuAc) $\beta 1$ configuration. Neurology. 42:686689.

19. Willison, H.J., G. Paterson, J. Veitch, G. Inglis, and S.C. Barnett. 1993. Peripheral neuropathy associated with monoclonal IgM anti-Pr2 cold agglutinins. J. Neurol. Neurosurg. Psychiatry. 56:1178-1184.

20. Brindel, I., J. Preud'Homme, J. Vallat, D. Vincent, J. Vasquez, and M. Jauberteau. 1994. Monoclonal IgM reactive with several gangliosides in a chronic relapsing neuropathy. Neurosci. Lett. 181:103-106.

21. Herron, B., H.J. Willison, J. Veitch, D. Roelcke, L.S. Illis, and F.E. Boulton. 1994. Monoclonal IgM cold agglutinins with anti-Pr1d specificity in a patient with peripheral neuropathy. Vox. Sang. 67:58-63.

22. Roelcke, D., and H. Kreft. 1984. Characterization of various anti-Pr cold agglutinins. Transfusion (Bethesda). 24:210-213.

23. Hays, A.P., N. Latov, M. Takatsu, and W.H. Sherman. 1987. Experimental demyelination of nerve induced by serum of patients with neuropathy and an anti-MAG IgM M-Protein. Neurology. 37:242-256.

24. Willison, H.J., B.D. Trapp, J. Bacher, M. Dalakas, J.W. Griffin, and R.H. Quarles. 1988. Demyelination induced by intraneural injection of human anti-myelin-associated glycoprotein antibodies. Muscle \& Nerve. 11:1169-1176.

25. Tatum, A.H. 1993. Experimental paraproteinaemic neuropathy: demyelination by passive transfer of human IgM anti-myelin-associated glycoprotein antibody. Ann. Neurol. 33:502-506.

26. Monaco, S., S. Ferrari, B. Bonetti, G. Moretto, M. Kirshfink, E. Nardelli, E. Nobile-Orazio, G. Zanusso, N. Rizzuto, and F. Tedesco. 1995. Experimental induction of myelin changes by anti-MAG antibodies and terminal complement complex. J. Neuropathol. Exp. Neurol. 54:96-104.

27. Schwerer, B., H. Lassmann, K. Kitz, and H. Bernheimer. 1986. Ganglioside GM1, a molecular target for immunological and toxic attacks: similarity of neuropathological lesions induced by ganglioside antiserum and cholera toxin. Acta Neuropathol. 72:55-61.

28. Thomas, F.P., W. Trojaborg, C. Nagy, M. Santoro, S.A. Sadiq, N. Latov, and A.P. Hays. 1991. Experimental autoimmune neuropathy with anti-GM1 antibodies and immunoglobulin deposits at nodes of Ranvier. Acta Neuropathol. 82:378-383.

29. Santoro, M.A. Uncini, M. Corbo, S.M. Staugaitis, F.P. Thomas, A.P. Hays, and N. Latov. 1992. Experimental conduction block induced by serum from a patient with anti-GM1 antibodies. Ann. Neurol. 31:385-390.

30. Arakasi, K., S. Kusonoki, N. Kudo, and I. Kanazawa. 1993. Acute conduction block in vitro following exposure to anti-ganglioside sera. Muscle \& Nerve. 16:587-593.

31. Roberts, M., H.J. Willison, A. Vincent, and J. Newsom-Davis. 1995. Multifocal motor neuropathy human sera block distal motor nerve conduction in mice. Ann. Neurol. 38:111-118.

32. Roberts, M., H.J. Willison, A. Vincent and J. Newsom-Davis. 1994. Serum factor in Miller Fisher variant of Guillain Barré syndrome and neurotransmitter release. Lancet. 343:454-455.

33. Thompson, K.M., D.W. Hough, P.J. Maddison, M.D. Melamed, and N. Hughes-Jones. 1986. The efficient production of stable human monoclonal antibody-secreting hybridomas from EBV-transformed lymphocytes using the mouse myeloma A63-Ag8.653 as a fusion partner. J. Immunol. Methods. 94:712 .

34. Willison, H.J., G. Paterson, P.G.E. Kennedy, and J. Veitch. 1994. Cloning of human anti-GM1 antibodies from motor neuropathy patients. Ann. Neurol. 35:471-478.

35. Liddell, J.E., and A. Cryer. 1991. Characterisation, purification and labelling. In A Practical Guide to Monoclonal Antibodies. John Wiley and Sons Ltd. Chichester, UK. 105-138.

36. Mancini, G., A.O. Carbonara, and J.F. Heremans. 1965. Immunochemical quantitation of antigens by single radial immunodiffusion. Immunochemistry. 2:235-254.

37. Keir, G., R.W. Luxton, and E.J. Thompson. 1990. Isoelectric focusing of cerebrospinal fluid IgG: an annotated update. Ann. Clin. Biochem. 162:156159

38. Chomczynski, P., and N. Sacchi. 1987. Single step method of RNA isolation by acid guanidinium thiocyanate phenol-chloroform. Ann. Biochem. 162: $156-159$.

39. Campbell, M.J., A.D. Zelenetz, S. Levy, and R. Levy. 1992. Use of family specific leader region primers for PCR amplification of the human heavy chain variable region gene repertoire. Mol Immunol. 29:193-203.

40. Larrick, J.W., L. Danielsson, C.A. Brenner, E.F. Wallace, M. Abrahamson, K.E. Fry, and C.A.K. Borrebaeck. 1989. Polymerase chain reaction using mixed primers: cloning of human monoclonal antibody variable region genes from single hybridoma cells. Biotechnology. 7:934-938. 
41. Fishman, P.H., T. Pacuszka, and P.A. Orlandi. 1993. Gangliosides as receptors for bacterial enterotoxins. Adv. Lipid Res. 25:165-187.

42. Matsuda, F., E.K. Shin, H. Nagaoka, R. Matsumura, M. Haino, Y. Fukita, S. Taka-ishi, T. Imai, J.H. Riley, R. Anand, et al. 1993. Structure and physical map of 64 variable segments in the $3^{\prime} 0.8$-megabase region of the human immunoglobulin heavy-chain locus. Nat. Genet. 3:88-94.

43. Williams, S.C., and G. Winter. 1993. Cloning and sequencing of human immunoglobulin V lambda gene segments. Eur. J. Immunol. 23:1456-1461.

44. Uemura, K., D. Roelcke, Y. Nagai, and T. Feizi. 1984. The reactivities of human erythrocyte autoantibodies anti- $\mathrm{Pr}_{2}$, antiGd, $\mathrm{Fl}$ and $\mathrm{Sa}$ with gangliosides in a chromatogram binding assay. Biochem. J. 219:865-874.

45. Friedman, D.F., E.A. Cho, J. Goldman, C.E. Carmack, E.C. Besa, R.R. Hardy, and L.E. Siberstein. 1991. The role of clonal selection in the pathogenesis of an autoreactive human B cell lymphoma. J. Exp. Med. 174:525-537.

46. Tomlinson, I.M., G. Walter, J.D. Marks, M.B. Llewelyn, and G. Winter. 1992. The repertoire of human germline VH sequences reveals about fifty groups of $\mathrm{VH}$ segments with different hypervariable loops. J. Mol. Biol. 227: 776-798.

47. Kabat, E.A., T.T. Wu, H.M. Perry, K.S. Gottesman, and C. Foeller. 1991. Sequences of proteins of immunological interest. US Department of Health and Human Services, Public Health Service, National Institutes of Health, NIH Publication Number 91-3242.

48. Paterson, G., G. Wilson, P.G.E. Kennedy, and H.J. Willison. 1995. Analysis of anti-GM1 antibodies cloned from motor neuropathy patients demonstrates diverse variable region gene usage with extensive somatic mutation. $J$. Immunol. 155:3049-3059.

49. Thompson, K.M., J. Sutherland, G. Barden, M.D. Melamed, I. Randen, J.B. Natvig, V. Pascual, J.D. Capra, and F.K. Stevenson. 1991. Human monoclonal antibodies against blood group antigens preferentially express a $V_{H} 4-21$ variable region gene-associated epitope. Scand. J. Immunol. 34:509-518.

50. Silberstein, L.E., L.C. Jefferies, J. Goldman, D. Friedman, J.S. Moore, P.C. Nowell, D. Roelcke, W. Pruzanski, J. Roudier, and G.J. Silverman. 1991. Variable region gene analysis of pathologic human autoantibodies to the related $\mathrm{i}$ and $\mathrm{l}$ red blood cell antigens. Blood. 78:2372-2386.

51. Pascual, V., K. Victor, D. Lelsz, M.B. Spellerberg, T.J. Hamblin, K.M. Thompson, I. Randen, J. Natvig, J.D. Capra, and F.K. Stevenson. 1991. Nucleotide sequence analysis of the $\mathrm{V}$ regions of two IgM agglutinins: Evidence that the $\mathrm{V}_{\mathrm{H}} 4-21$ gene segment is responsible for the major cross reactive idiotype. $J$. Immunol. 146:4385-4391.

52. Jefferies, L.C., C.M. Carchidi, and L.E. Silberstein. 1993. Naturally occurring anti-i/l cold agglutinins may be encoded by different $\mathrm{V}_{\mathrm{H}} 3$ genes as well as the $\mathrm{V}_{\mathrm{H}}$ 4-21 gene segment. J. Exp. Med. 92:2821-2833.

53. Chiba, A., S. Kusonoki, T. Shimizu, and I. Kanazawa. 1992. Serum IgG antibody to ganglioside GQ1b is a possible marker of Miller Fisher syndrome. Ann. Neurol. 31:677-679.

54. Willison, H.J., J. Veitch, G. Paterson, and P.G.E. Kennedy. 1993. Miller Fisher syndrome is associated with serum antibodies to GQ1b ganglioside. $J$. Neurol. Neurosurg. Psychiatry. 56:204-206.

55. Yuki, N., S. Sato, S. Tsuji, T. Ohsawa, and T. Miyatake. 1993. Frequent presence of anti-GQ1b antibody in Fisher's syndrome. Neurology. 43:414-417.

56. Takigawa, T., H. Yasuda, R. Kikkawa, Y. Shigeta, T. Saida, and H. Kitasato. 1995. Antibodies against GM1 ganglioside affect $\mathrm{K}+$ and $\mathrm{Na}+$ currents in isolated rat myelinated nerve fibers. Ann. Neurol. 37:436-442.

57. Montecucco, C., G. Schiavo, Z. Goa, E. Bauerlein, P. Bouquet, and B.R. DasGupta. 1988. Interaction of Botulinum and tetanus toxins with the lipid bilayer surface. Biochem. J. 251:379-383.

58. Willison, H.J., and P.G.E. Kennedy. 1993. Gangliosides and bacterial toxins in Guillain Barre syndrome. J. Neuroimmunol. 46:105-112. 